\title{
Composition chimique des protozoaires et des bactéries libres du rumen de vaches
}

\author{
KTanan ${ }^{1}$, G Blanchart ${ }^{2}$, C Poncet ${ }^{3}, \mathrm{JC}$ Robert ${ }^{1 *}$, G Dumont ${ }^{1}$, E Desarménien ${ }^{1}$ \\ 1 Rhone Poulenc Animal Nutrition, 03600 Commentry; \\ 2 INRA-ENSAIA, 54500 Vandoouvre-lès-Nancy; \\ 3 INRA, station de recherche sur la nutrition des herbivores, 63122 Saint-Genès-Champanelle, France
}

L'acide diaminopimélique (DAPA), considéré comme marqueur bactérien, semble être présent dans les protozoaires qui sont capables de le métaboliser (Denholm et Ling, 1989). Pour vérifier cette hypothèse, nous avons isolé les protozoaires du rumen, déterminé leurs teneurs en DAPA, matière organique (MO), azote $(\mathrm{N})$ et acides aminés (AA) et nous les avons comparées à celles des bactéries libres du rumen.

Trois vaches laitières taries fistulées du rumen et du duodénum reçoivent une ration d'ensilage d'herbe et de concentré $(50 / 50$, "H») en période 1 et d'ensilage de maïs et de concentré $(70 / 30$, “ $\mathrm{Mm}$ ) en période 2, à raison de $8 \mathrm{~kg}$ de $\mathrm{MS} / \mathrm{j}$ distribués en 8 repas égaux. À chaque période, le rumen des vaches est entièrement vidé une fois au milieu de l'intervalle séparant 2 repas. Une partie aliquote est prélevée, filtrée $(300 \mu \mathrm{m})$ et le reste replacé dans le rumen. Le résidu est lavé 2 fois ( $\mathrm{NaCl} 9 \mathrm{~g} /$ ) et la solution de lavage est mélangée au filtrat. Les bactéries libres sont isolées à partir de ce mélange selon une double centrifugation ( $1000 \mathrm{~g}, 20 \mathrm{~min}, 4^{\circ} \mathrm{C}$ puis $23000 \mathrm{~g}, 30$ $\min , 4^{\circ} \mathrm{C}$ ). Les protozoaires sont isolés également à partir d'une centrifugation de ce mélange $\left(500 \mathrm{~g}, 2 \mathrm{~min}, 4^{\circ} \mathrm{C}\right.$ ). Inclus dans le culot, ils sont purifiés par une aspiration des particules, un lavage et une nouvelle centrifugation $(500 \mathrm{~g}, 2$ $\min , 4^{\circ} \mathrm{C}$ ), cette opération est effectuée 3 fois.

Pour les 2 régimes, les protozoaires ont des teneurs en $\mathrm{N}$ et un rapport DAPA/N plus faibles que ceux des bactéries libres. La part de I'N protéique dans I' $N$ total ainsi que celle des AA essentiels (AAE) dans les AA totaux (AAT) sont, au contraire, plus élevées que pour les bactéries libres. Le régime a eu un effet sur les teneurs en $\mathrm{N}$ des protozoaires et des bactéries libres. Seuls les protozoaires du régime $M$ ont une teneur plus faible en AAT. Les résultats rejoignent ceux obtenus par d'autres auteurs ayant utilisé une autre méthode d'isolement des protozoaires (Tamminga, 1975). L'essai confirme la présence de DAPA dans les protozoaires. Si les protozoaires transitent dans le duodénum, une part du DAPA duodénal pourrait leur être attribuée et ce DAPA serait sous forme de DAPA libre (Tamminga, 1975). Ces résultats limitent l'utilisation du DAPA comme marqueur bactérien.

Denholm AM, Ling JR (1989) App/ Environ Microbiol 55, 212-218

Tamminga S (1975) Z Tierphysiol Tierernährg Futtermittelkde 35, 337-346

Tableau l. Composition chimique des protozoaires et des bactéries libres du rumen, dans le cas de 2 rations (moyenne, $n=3$ ).

\begin{tabular}{|c|c|c|c|c|c|}
\hline & \multicolumn{2}{|c|}{ Ration $\mathrm{H}$} & \multicolumn{2}{|c|}{ Ration $M$} & \multirow[b]{2}{*}{ ETA } \\
\hline & $B L$ & PRT & $B L$ & PRT & \\
\hline $\begin{array}{l}\text { N (\% MO) } \\
\text { AAT * }(\% \mathrm{MO}) \\
\text { DAPA }(\% \mathrm{~N}) \\
\text { AA-N }(\% \mathrm{~N}) \\
\text { AAE (\% AAT) }\end{array}$ & $\begin{array}{c}9,48 \text { aA } \\
46,5 \text { aA } \\
3,76 \text { a } \\
66,9 \mathrm{~b} \\
51,1^{b}\end{array}$ & $\begin{array}{c}7,74^{\mathrm{bA}} \\
44,0^{\mathrm{aA}} \\
0,83^{\mathrm{b}} \\
77,6^{\mathrm{a}} \\
52,7^{\mathrm{a}}\end{array}$ & $\begin{array}{c}9,11 \text { aB } \\
45,8 \text { aA } \\
3,53 \text { a } \\
68,3 \text { b } \\
50,9 \text { b }\end{array}$ & $\begin{array}{c}6,87^{\mathrm{bB}} \\
37,6^{\mathrm{bB}} \\
0,98^{\mathrm{b}} \\
74,8^{\mathrm{a}} \\
52,7^{\mathrm{a}}\end{array}$ & $\begin{array}{l}0,21 \\
1,6 \\
0,40 \\
2,2 \\
0,4\end{array}$ \\
\hline
\end{tabular}

Effets significatifs $(P<0,05)$ du type de microorganisme $\left({ }^{a}, b\right)$ et du régime $\left({ }^{A},{ }^{B}\right)$. ${ }^{*}$ Aat $=$ Thr, Cys, Val, Met, lle, Leu, Phe, Lys, His, Arg et Asp, Ser, Glu, Gly, Ala, Tyr.

\footnotetext{
* Correspondance et tirés à part
} 